\title{
LA DECONSTRUCCIÓN DE LA AMISTAD-ENEMISTAD: VERDAD Y MUJERES. A PROPÓSITO DEL ASÍ HABLÓ ZARATUSTRA DE NIETZSCHE
}

The friendship-enmity relationship deconstruction: truth and women. Considering the book Thus spoke Zarathustra by Nietzsche

\author{
Pedro Lastra Gutiérrez \\ Universidad Adolfo Ibáñez, Santiago, Chile \\ lastrapedroprofesor@gmail.com
}

\section{Resumen}

Se suele afirmar, sin mayor estudio, que Nietzsche es un filósofo misógino. Esto debido a las polémicas y fallidas relaciones de amistad y de amor con familiares y amigos, lo que ha contribuido a interpretar algunos parágrafos del libro primero del Así Habló Zaratustra como una catarsis y un ataque a las mujeres y a lo que ellas representan. En el presente artículo realizaremos un breve análisis genealógico del capítulo "Del amigo", dilucidando de manera deconstructiva el estilo y propósito del autor en torno a la verdad, la mujer y la amistad, reconociendo en su escritura un intento por romper con los principios de la racionalidad que sostienen el dualismo de base en torno a la figura femenina impuesta desde un orden heteropatriarcal.

Palabras clave: Zaratustra, feminismo, deconstrucción, genealogía, amistad

\begin{abstract}
It is often claimed without further study that Nietzsche is a misogynist philosopher. This is due to the controversial and failed relationships of friendship and love he had with family and friends, which has helped to interpret some paragraphs of the first book of Thus Spoke Zarastustra as a catharsis and an attack on women and what they represent. In the present article we will make a brief genealogical analysis of the chapter called "On my honour, my friend", elucidating in a deconstructive manner the and purpose of the author regarding truth, woman and friendship, recognizing in his writing an attempt to break with the principles of rationality that sustain the basic dualism around the female figure imposed from a heteropatriarchal order.
\end{abstract}

Keywords: Zarathustra. Feminism. Deconstruction, genealogy, friendship.

Fecha de Recepción: 19/06/2019 - Fecha de Aceptación: 20/12/2019 
Cómo puede sorprender que con ello se haga visible mucho que es racional y loco, mucha ternura impetuosa, derrochada incluso sobre problemas que tienen una piel erizada y que no parecen ser apropiados para ser acariciados y seducidos.

Nietzsche, La Ciencia Jovial

\section{La génesis de una sospecha}

¿Por qué percibimos a Nietzsche como un filósofo misógino? ¿Es tal vez por ese texto que dice "si andas con mujeres, no te olvides del látigo ( $c f$. Nietzsche 2010109 y ss)"? ¿Qué cambios, a partir de su filosofía pueden apreciarse respecto de esta relación irresuelta entre el hombre y la mujer? ¿Por qué en la mujer no hay amistad y solo existe un tirano que el filósofo llama amor? ¿Por qué el constante ataque de este filósofo a lo femenino y a lo que representa? En otros textos reclama y compara a los ilustrados con hombres "afeminados", y a los dogmáticos como individuos incapaces de conquistar a una "hembra"; y luego, sin que nos recuperemos de esos golpes, nos señala que la verdad es semejante a esta "mujer" que supuestamente menosprecia y que solo "ama a un guerrero". Indudablemente la amistad no es lo mismo que el amor, pero si no existe amistad ni amor entre hombres y mujeres, entonces, ¿qué hay? Existen variados discursos que emancipan a la mujer, que la llaman a reclamar justicia en materia de derechos fundamentales, cívicos y laborales, quemando y crucificando todo lo que "huela" a patriarcado. En estos contextos, ¿seguimos siendo enemigos sin derecho a la amistad?

Los traductores de Nietzsche al español (cf. Jara 1998; Sánchez Pascual 2010) han asociado los polémicos parágrafos sobre la mujer a su experiencia vital con tres figuras reales: Cósima Wagner, Lou Salome y su hermana Elizabeth. Supuestamente "ellas" tuvieron un impacto sobre el tono y el propósito de los aforismos relacionados con lo femenino. Pero suponer aquello significa descartar cualquier tipo de aporte del filósofo al debate contemporáneo sobre feminismo y filosofía.

Por este motivo, el objetivo de la presente investigación será realizar un breve análisis genealógico sobre los conceptos claves de amistad y enemistad, presentes en discurso del Así habló Zaratustra titulado "Del amigo"1, por lo cual

\footnotetext{
${ }^{1}$ Nietzsche señala respecto de esto: “Durante mucho tiempo se ha ocultado en la mujer un esclavo y un tirano. Por ello la mujer no es todavía capaz de amistad: solo conoce el amor. En el amor de la mujer hay injusticia y ceguera frente a todo lo que ella no ama. Y hasta en el amor sapiente de la mujer continúa habiendo agresión inesperada y rayo y noche al lado de la luz. La mujer no es todavía capaz de amistad: gatas continúan siendo siempre las mujeres, y pájaros. $\mathrm{O}$, en el mejor de los casos, vacas. La mujer no es capaz de amistad. Pero decidme, varones, ¿Quién de vosotros es capaz de amistad? ¡Cuánta pobreza, varones, y cuánta avaricia hay en vuestra alma! Lo que
} 
procederemos ensayando una reflexión deconstructiva de los textos nietzscheanos que apuntan al tratamiento ambivalente e inasible de lo femenino, intentando desentrañar el fundamento de esta "enemistad" y visualizando el lenguaje simbólico que utiliza el filósofo para mostrar esta realidad velada.

\section{El timbre inaudible del aforismo nietzscheano}

El uso constante de símbolos y metáforas en los textos nietzscheanos no permite seguir con facilidad los "hilos" argumentativos, al contrario, existen "tonos" en el uso del lenguaje y constantes auto referencias en Nietzsche que son imposibles de evitar; es más, debemos hacer el esfuerzo de participar de "ellos" para estar en "sintonía" y dilucidar, en medida de lo posible, el propósito de su propuesta filosófica ${ }^{2}$. Teniendo en consideración lo anterior: ¿por qué son tan especiales los aforismos nietzscheanos? ¿Qué los hace tan únicos y difíciles de dilucidar? ¿O son una forma en que Nietzsche decidió trabajar filosóficamente para ahuyentar a los "malos lectores", a los científicos e ilustrados aduladores de "ídolos"?

Explícitamente sí. El Así habló Zaratustra es todo lo que un libro de filosofía no debería ser, pero hay que entender que El nacimiento de la tragedia, Aurora, Humano, demasiado humano y la Ciencia Jovial le preceden en cuestión de estilos. Nietzsche, a sabiendas y quizás no tanto, tiene la ventaja de instalar una nueva forma de enfrentar la verdad de su filosofía, a costa de hacer de su filosofía un método.

Todo estilo está determinado por el contenido ${ }^{3}$, y si el propósito de Nietzsche era dinamitar la modernidad, utilizar la misma metodología de los filósofos que él llamaba "dogmáticos" habría sido absurdo. La cuestión es que los aforismos son la forma renovada del enigma, la posibilidad de recrear el regreso al

vosotros dais al amigo, eso quiero darlo yo hasta a mi enemigo, y no por eso me habré vuelto más pobre" (2002b 97-98).

2 En el decir de Deleuze, “Nietzsche integra en la filosofía dos medios de expresión, el aforismo y poema. Esas mismas formas implican una nueva concepción de la filosofía, una nueva imagen del pensador y del pensamiento. El ideal del conocimiento, el descubrimiento de la verdad, los sustituye Nietzsche por la interpretación y la evaluación (...) Precisamente el aforismo es el arte de interpretar y la cosa por interpretar; el poema, a la vez arte de evaluar y la cosa de evaluar. El intérprete es fisiólogo o médico, aquel que considera los fenómenos como síntomas ya habla mediante aforismos. El evaluador es el artista, el considera y crea "perspectivas" el que habla mediante el poema. El filósofo del futuro es artista y médico - en una palabra, legislador" (23-24).

${ }^{3}$ Susana Münnich cuenta una anécdota sobre la vez que intento publicar un trabajo académico en primera persona en vez en la tradicional tercera que corresponde a la mayoría de los ensayos filosóficos: "La seriedad filosófica le resultaba incompatible con la intimidad (al editor), la subjetividad del pronombre "yo", reservado a la poesía y los géneros epistolares", agrega concluyendo que ha "aprendido que el estilo de un escrito es inseparable de su contenido" (9; énfasis nuestro). 
laberinto ${ }^{4}$, en donde el héroe y el sabio se juegan la vida en descifrar una respuesta. En este punto, el aforismo y la metáfora son el juego del hombre "surrealista" (el dadaísta al cual se refería Feyerabend); esto permite realizar una epistemología alternativa y opuesta al canon académico. En este juego el lector debe "rumiar" lo que lee, las palabras sencillas; debe escuchar la sospecha y experimentar, junto con el autor, la deconstrucción de los discursos hegemónicos. En conclusión, esta epistemología nietzscheana no enseña sobre filosofía, sino que permite filosofar.

Pero la situación es distinta para el sujeto que se adentra de manera analítica en los textos nietzscheanos. No cabe duda recalcar que la tarea principal de esta breve investigación es sugerir y mostrar "el hilo de las analogías y de los símbolos, encontrar una temática más imaginaria que discursiva, más afectiva que racional y mucho menos próxima al concepto que al deseo" (Foucault 1970 250) y de esta forma dar una coherencia a las contradicciones evidentes de los textos de Nietzsche.

En primer lugar, debemos reconocer que, en nuestro contexto, el cruce entre feminismo y deconstrucción es uno de los acontecimientos más importantes a la hora de entender las nuevas interpretaciones del texto nietzscheano.

Siguiendo esta crítica, Jacques Derrida y Sara Kofman desarrollaron la posibilidad de repensar la figura de la mujer y lo femenino en la herencia nietzscheana. En este pensamiento deconstructivo el debate en torno al ser aparece como inseparable de la cuestión referida a la diferencia sexual. Esto puede verse prefigurado en la caracterización de la metafísica occidental en términos de falocentrismo. Desde Nietzsche la subjetividad es pensada en términos de corporalidad como entrecruzamientos de fuerzas que permiten explicar los movimientos, según Kofman, en torno a la idea de mujer afirmativa, y los de Derrida en términos de "operación femenina". Estos desplazamientos en el modo de pensar la subjetividad permiten hablar de fuerzas femeninas y fuerzas masculinas que se entrecruzan en cada cuerpo, sea hombre o mujer, con el resto de las fuerzas: salud y enfermedad, jovialidad y resentimiento (Lussich 235-300).

A continuación, tomando en cuenta lo anterior, expondremos los subsuelos conceptuales sobre la mujer y lo femenino con cuales trabajó nuestro filósofo.

Dijo Nietzsche que una cosa era él y otra sus textos. Por ende, dejemos de hablar de él y pensemos en él, y no por la necesidad de evitar los efectos telúricos de su pensamiento, sino para evitar toda clase de proselitismo alrededor de su

${ }^{4}$ Después del devastador menosprecio de la comunidad de filólogos en torno a la publicación del Nacimiento de la tragedia, Nietzsche optará y mantendrá una postura en la cual siempre aludirá a un grupo exclusivo de oyentes o filósofos, no seguidores sino espíritus libres quienes poseerán ciertas cualidades; una de aquellas es una fascinación por lo vedado: “Una predilección de la fuerza por problemas para los que hoy nadie tiene valor; el valor de lo prohibido; la predestinación al laberinto" (Nietzsche 2002a 29). 
persona. Además, como expondremos más adelante con mayor profundidad, Nietzsche también juega a enmascararse. Entonces, ¿a qué es lo que juega este filósofo? ¿A asfixiarnos en el vacío de la muerte de Dios? ¿Ejercer en nuestra subjetividad una Transvaloración? La verdad es que no, porque eso es lo que estamos acostumbrados a escuchar de él, y es en cierta manera lo que esperamos escuchar.

Para revertir esta situación la clave de lectura es Schopenhauer, autor del que Nietzsche trata de desembarazarse continuamente.

En el prólogo a la primera edición de El mundo como voluntad y representación, Schopenhauer hace una sutil distinción entre un sistema de pensamiento y un único pensamiento que, por extenso que pueda ser, puede conservar la unidad más perfecta, si a efecto de su transmisión se deja descomponer en partes sin perder su orgánica. Tiempo más tarde, golpeado por el hado impredecible y el silencio de sus contemporáneos, el filósofo del pesimismo descarga su pluma contra la academia (esta actitud también la adoptará Nietzsche). En el prólogo de la segunda edición dice:

Yo diría que incluso ninguna época puede ser más adversa a la filosofía que aquella en que se abusa de ella como instrumento político por un lado o se utiliza desdeñosamente como medio de subsistencia por el otro. ¿O acaso se cree que en medio de tal afán y semejante barullo puede hacerse patente esa verdad a la que nadie atiende? La verdad no es una puta que se arroje al cuello de quienes no tienen ganas de ella; más bien es una beldad tan esquiva que incluso quien sacrifica todo por ella tampoco puede estar seguro de obtener sus favores (Schopenhauer 96)

¿Cuál es ese pensamiento que ronda la filosofía nietzscheana? El quiebre de Nietzsche con la tradición filosófica radica en unas cuantas preguntas que hacen eco del cuestionamiento de Schopenhauer:

Suponiendo que la verdad sea una mujer - ¿cómo?, ¿no está justificada la sospecha de que todos los filósofos, en la medida en que han sido dogmáticos han entendido poco de mujeres?, ¿de qué estremecedora seriedad, la torpe insistencia con que hasta ahora han sabido acercarse a la verdad eran medios inhábiles e ineptos para conquistar los favores de una hembra? Lo cierto es que la verdad no se ha dejado conquistar (Nietzsche 2007 19).

La consistencia de este único pensamiento desató la sospecha sobre la racionalidad de la ilustración y los valores democráticos de la modernidad, continuadores según Nietzsche de los ideales ascéticos y nihilistas. A nuestro entender, esto explica la utilización del potente símbolo: mujer-sabiduría-verdad, para exponer los valores reactivos y decadentes contra la vida. Es imaginable la reacción de la academia y el silencio de los filósofos sobre el prólogo de Mas allá del bien y del mal. Esta identificación trae consigo el temor a lo irracional y empuja a los metafísicos a declarar abiertamente lo que han pensado tradicionalmente sobre la mujer y lo 
femenino: seducción, metáfora, lo indescifrable, ergo, el peligro.

Hay una imagen en Ecce Homo que llama la atención por su punzante ironía, y dice así:

Pero a cualquier lugar que llego, aquí en Turín, por ejemplo, todos los rostros se alegran y se ponen benévolos al verme. Lo que más me ha lisonjeado hasta ahora es que algunas viejas vendedoras de frutos no descansan hasta haber escogido para mí los racimos más dulces de sus uvas. Hasta ese punto hay que ser filósofo (Nietzsche 2005 66).

La lectura deconstructiva permite reconocer en este enunciado una referencia bíblica, situada al final del libro del Eclesiástico: "Cuando yo era joven, antes de irme a recorrer el mundo deseaba ardientemente recibir sabiduría. Y ella vino a mí en toda su belleza. Yo la busqué hasta que di por fin con ella. Estaba en su punto como racimo maduro" (Eclo. $5113 \mathrm{ss}$ ).

Las referencias a la mujer como un fruto maduro es la imagen del deseo y la atracción masculina por la sabiduría. Claramente es una de las tantas sospechas nietzscheanas sobre los motivos ascéticos de los filósofos. Pero, simultáneamente, comprendemos que la atracción representa seducción y sometimiento: castración. Una castración que las figuras masculinas relacionadas con el conocimiento estaban dispuestas a asumir, para encontrar la "verdad", pero que trajo como consecuencia inevitable el rechazo de la mujer real y el peligro que representa su feminidad.

¿Es la atracción lo más peligroso en la mujer? Podríamos decir que sí, para alguien que tenga vocación por el saber. Es la "acción a distancia" lo que caracteriza a la mujer, el efecto estremecedor que provoca en el hombre como bien reconoce Derrida en Espolones:

La seducción de la mujer opera a distancia, la distancia es el elemento de su poder. Pero de ese canto, de ese encanto, hay que mantenerse a distancia; hay que mantenerse a distancia, y no sólo, como podría suponerse, para protegerse contra esa fascinación, sino también para experimentarla (Derrida 1981 26).

La cuestión es que Nietzsche al hablar sobre la mujer y su relación con el potente símbolo verdad-sabiduría no da pistas interpretativas, al contrario, teje un nudo de contradicciones que Susana Münnich llama deseo ambivalente: "tiene una fijación materna. Lo anima un deseo ambivalente. Quiere que esa mujer-madre, al mismo tiempo adorada y despreciada, se aleje de él. Pero también desea lo contrario: que esa mujer no abandone el cuidado del hogar" (Münnich 67). 


\section{La transvaloración de lo femenino en la filosofía de Nietzsche}

Volviendo al texto del Zaratustra de Nietzsche, ¿por qué la mujer está imposibilitada de amistad? ¿Es porque su presencia motiva el rechazo a la búsqueda de la verdad y del conocimiento? $\mathrm{O}$ ¿existe un valor o capacidad en la mujer que la inhabilita de compartir dichos sentimientos para con los hombres? Para responder a estas preguntas, nos vemos en la obligación de ensayar brevemente una deconstrucción de la amistad.

Como tesis sostenemos que la amistad fue, en el origen, una actividad exclusivamente destinada a los varones. La biología masculina carece del poder del alumbramiento, en su lugar establece pactos y alianzas, ergo, crea valores y establece la amistad como el signo de su fraternidad. Los hombres poseen una inclinación a "separarse", a ser solo ellos; en cambio, las mujeres tienen una tendencia a acoger en su seno a todo aquel que necesite de ellas. Si esto es así, ¿por qué Nietzsche insistió en la idea del tirano y del esclavo en el amor de la mujer?

Según nuestra interpretación, para nuestro filósofo, lo femenino representa en este contexto el amor/compasión, la praxis del nihilista es su compasión por el prójimo ( $c f$. Nietzsche 2002a 31). En cambio, los hombres, en su masculinidad castrada de preñez, crean el amor/amistad para compensar esta falta constitutiva.

Si nos atrevemos a agrupar los discursos de Nietzsche de la primera parte del Zaratustra, y hacemos un subconjunto entre los aforismos "Del amigo", "De las mil metas y la "única" meta", "Del amor al prójimo", "Del camino del creador", "De viejecillas y de jovencillas" y "Del hijo y del matrimonio", vamos viendo de qué manera se enhebran como ejes conceptuales el amor, la amistad y la soledad. Esto allana el parto de nuevos principios que conducen a la creación valórica, a saber, los que están a la base de una estética de la existencia.

Tradicionalmente la crítica se ha concentrado en torno a los ejes de las trasformaciones del espíritu para el avenimiento del superhombre: la muerte de Dios o la idea del eterno retorno. Pero se hace preciso recalcar que el Zaratustra fue editado y publicado por partes, y que el peso de los capítulos del libro primero, a mi entender, son los dolores de parto para estos hombres nuevos, que es una clara referencia a lo alude Schopenhauer al decir que "la razón es de naturaleza femenina: sólo puede dar a luz después de haber sido preñada" (Schopenhauer 183)

En este sentido se puede plantear que Nietzsche es el pensador de la preñez, "el pensador del embarazo. Esto puede verificarse en cualquier parte. Lo ensalza no menos en el hombre que en la mujer. Y teniendo en cuenta que lloraba con facilidad y hablaba de su pensamiento como una mujer en cinta lo haría de su hijo, a menudo lo imagino vertiendo lágrimas sobre su vientre" (Derrida 1981 37). 
Si volvemos nuevamente al análisis de los parágrafos de Nietzsche en el Zaratustra, podemos ver un discurso reactivo opuesto al feminismo de la mujer que quiere igualarse al hombre moderno en su nihilismo decadente de tirano y esclavo. Mostrando que el "ideal de igualdad" no trae consigo nuevas formas de amistad, al contrario, somete a la mujer a nuevas tiranías políticas y conceptuales.

Lo anterior tiene sentido si lo entendemos en el siguiente contexto: en la historia de las formas de relacionarnos con el medio y los demás existe la manifestación de una clase de subjetividad como fenómeno propio de la modernidad, momento que Foucault (2012 36) llamó el momento cartesiano. En esta dimensión la conciencia se conoce y reconoce objetivamente la realidad, transformándose así en el paradigma de racionalidad y el progreso.

Para Nietzsche la interpretación valórica de la realidad no es más que uno de los tantos intentos creativos por salvaguardar la subjetividad del individuo; un subterfugio que utilizaron los modernos para seguir salvando el alma. Los ideales de los ilustrados y los republicanos son tan nihilistas como el cristianismo y las religiones de oriente, ambos, en cierta forma, patriarcales. Para el filósofo, cualquier discurso autoproclamado democrático en el último cuarto de siglo habría tratado de defender esa porción de derechos "inalienables" pero universalmente asexuados, promoviendo a la par la tolerancia y la amistad cívica a pesar de las evidentes diferencias sociales, económicas, sexuales y de género.

Ahora intentaremos un breve ensayo genealógico sobre amistad-enemistad entre hombres y mujeres, y de este modo visualizar mejor las motivaciones nietzscheanas. Podríamos encontrar algunas respuestas en Freud. En Tótem y tabú la vinculación totémica es superior al lazo sanguíneo en cuanto ordenamiento social, ya que prescribe el tabú del incesto e impone la exogamia. Padres e hijos censuran el deseo sobre las hembras del propio clan familiar o, desde otro punto de vista, existe una restricción porque existe el miedo al castigo de poseer lo "propio", debiendo prevalecer el deseo de lo "ajeno". Nuestra pregunta parece remitir al origen de las normas y a los derechos que salvaguardan la amistad entre los sexos:

El aspecto social del totemismo se plasma sobre todo en un mandamiento de rigurosa observancia y en una enorme restricción. Los miembros de un clan totémico son hermanos y hermanas (...) Los lazos totémicos son más fuertes que los familiares tal como nosotros lo entendemos; y no coinciden con estos, ya que por regla general la trasmisión del tótem se produce por herencia materna y originariamente la herencia paterna acaso ni siquiera regía (Freud 1991a 108).

Frente a esta situación surgen otra serie de interrogantes: ¿podemos encontrar aquí una primera manifestación de la complicidad original? ¿Cómo se hace posible fundamentar los lazos que unen ambos sexos y los mantienen unidos? ¿De qué manera habrán resuelto este dilema las primeras civilizaciones? ¿En qué momento 
se quiebra esta convivencia? Una respuesta tentativa la podemos encontrar en el Malestar en la cultura de Freud:

El descuido del lenguaje en el empleo de la palabra "Amor" designa el vínculo entre varón y mujer, que fundaron una familia sobre la base de sus necesidades genitales; pero también se da ese nombre a los sentimientos positivos entre padres e hijos, entre los hermanos dentro de una familia, aunque por nuestra parte debemos describir tales vínculos como amor de meta inhibida, como ternura. Es que el amor de meta inhibida fue en su origen un amor plenamente sexual, y lo sigue siendo en el inconsciente de los seres humanos. Ambos, el amor plenamente sensual y la meta inhibida, desbordan a la familia y establecen nuevas ligazones con personas hasta entonces extrañas. El amor genital lleva a la formación de nuevas familias; el de meta inhibida a "fraternidades" que alcanzan importancia cultural porque escapan a muchas de las limitaciones del amor genital: por ejemplo, a su carácter exclusivo (Freud 1991b 100).

Siguiendo la misma línea argumentativa Derrida, en Políticas de la amistad, enfatiza lo siguiente:

La fratriarquía puede comprender a los primos y a las hermanas, pero, como veremos, comprender quiere decir neutralizar. Comprender puede llevar a olvidar, por ejemplo, con la "mejor intención del mundo", que la hermana no proporciona jamás un ejemplo dócil para el concepto de fraternidad. Por eso se la quiere hacer dócil, y ahí está toda la educación política. ¿Qué pasa cuando, por hacer caso a la hermana, se hace de la mujer una hermana? ¿Y de la hermana un caso del hermano? Tal podría ser una de nuestras preguntas más insistentes, incluso sí, por haberlo hecho tal vez demasiado en otro lugar, evitemos convocar aquí a Antígona, de nuevo a aquí todas las Antígonas de la historia, sean o no dóciles a la historia de los hermanos que se viene contando desde hace milenios (Derrida 1998 13).

Las alianzas, los pactos y los matrimonios son cosa de una política sobre los cuerpos (claramente, hasta algunas décadas, los que quedan inhabilitados de cualquier trámite civil serio eran los interdictos, delincuentes, niños y mujeres). Por eso tal vez no nos incomoda la contingencia social hasta que toca el círculo íntimo de nuestras creencias, educación y valores. No nos incumbe a no ser que se involucren con "nuestras dóciles y frágiles" madres, esposas e hijas. ¿Por qué esta actitud tan displicente por aquel resto que no es nuestra familia? ¿Quiénes son el resto? ¿Extranjeros y/o bárbaros? Y si fuera el caso, ¿aquellos que se encuentran imposibilitados de mi amistad son necesariamente mis enemigos?

Raimundo Frei Toledo, quien realiza un recorrido histórico respecto a la relación entre política y amistad, resume tal situación de la siguiente forma:

Si se pone el foco de observación en la experiencia de la Antigüedad prima la distinción entre un nosotros y un ellos. Y esto quiere decir, se enfatiza la distinción entre los que pertenecen o no a un grupo, ya sea un grupo de combatientes como el séquito de Aquiles, ya sea los que participen del banquete y del simposio o ya sea los que están dentro del grupo de conversación del filósofo y pueden compartir su muerte. La mayor de las veces esta diferenciación se intensifica y subsume bajo la distinción de amigos y enemigos" (Frei 84). 
Si en la amistad pervive el sentido de la exclusividad es porque existe en nosotros una actitud misántropa que tensiona nuestra moral de rebaño. Y es por eso que, al utilizar la figura de la distancia, Nietzsche establece oposición a la compasiónproximidad de los valores cristianos y democráticos-; para él no es otra cosa que la intromisión sin autorización, la tiranía, la esclavitud de sentir y del pensar, la "expulsión de lo distinto" (Han 2017). Esos valores se ven representados en la figura de aquel ser andrógino e indefinido que roba la talega de monedas al hombre que decide apartarse del orden social en el cuadro de Pieter Brueghel llamado El misántropo ${ }^{5}$.

La cuestión parece ser que en la amistad y en el sexo, hombres y mujeres están relacionados política, económica y sexualmente; y aunque parezca una verdad evidente, el intento de depurar esas realidades por parte de los ilustrados y los demócratas llevó a la decadencia y a las formas reactivas de afrontar la realidad, dentro de las cuales también se encuentran las fórmulas valóricas del cómo apreciamos la amistad y su relación con lo femenino, recayendo por ende en nuestra comprensión sobre las mujeres.

En esta línea Nietzsche desenmascara la paradoja del igualitarismo, las sombras detrás de las luces, la falta de reciprocidad o la falta de un verdadero reconocimiento que existe entre los $\operatorname{sexos}^{6}$, que implicó finalmente, en el contexto nietzscheano, la redacción por parte del filósofo, de los polémicos parágrafos en donde el tono dramático, violento y a ratos misógino, no permite visualizar la crítica que realiza al movimiento feminista amparado en la subjetividad moderna.

${ }_{5}$ Debajo del cuadro se puede leer la siguiente leyenda: “Om dat de werelt is soe ongetru/ Daer om gha ic in de ru" (debido a que el mundo es tan traicionero/ me visto de luto) (traducción es nuestra). 6 Simone de Beauvoir expone claramente este punto en El segundo sexo (vale la extensa cita): "El hombre se olvida olímpicamente de que su anatomía comporta también hormonas, testículos. Considera su cuerpo como una relación directa y normal con el mundo que él cree aprehender en su objetividad, mientras considera el cuerpo de la mujer como apesadumbrado por todo cuanto lo especifica: un obstáculo, una cárcel. "la mujer es mujer en virtud de cierta falta de cualidades decía Aristóteles -. Debemos el carácter de las mujeres adoleciente de una imperfección natural." Y debemos a continuación, Santo Tomás decreta que la mujer es un "hombre fallido" y un ser "ocasional". Eso es lo que simboliza la historia del Génesis, donde Eva aparece como extraída, según la frase de Bossuet, es un "hueso supernumerario", de Adán. La humanidad es macho y el hombre define a la mujer no en sí misma, sino con relación a él, no la considera como un ser autónomo. "La mujer, el ser relativo...", escribe Michelet. Y así lo afirma Benda en el Rapport d'Uriel: "el cuerpo del hombre tiene sentido por sí mismo, abstracción hecha del de la mujer, mientras este último parece desprovisto de todo sentido si no se evoca al macho...el hombre se piensa sin la mujer. Ella no se piensa sin el hombre." Y ella no es otra cosa que lo que el hombre decida que sea; así se la denomina el "sexo", queriendo decir con ello que a los ojos del macho aparece esencialmente como un ser sexuado: para él, ella es sexo; por consiguiente, lo es absolutamente. La mujer se determina y se diferencia con relación al hombre, y no este con relación a ella; la mujer inesencial frente a lo esencial. Él es el sujeto, él es lo Absoluto ella es lo Otro" (18). 
Pero si colocamos atención a los resultados de su deconstrucción, nos damos cuenta que su metodología demolió el simulacro de significación universal que devoraba ambos sexos.

\section{Lo esencialmente otro}

A pesar de que Nietzsche se consagró como filósofo aislado de la academia, nunca rehuyó de la amistad. Esto se aprecia en la numerosa correspondencia que mantuvo con sus amigos y conocidos - y en un sentido opuesto a lo habitual, este material ha servido a sus estudiosos para exponer la fragilidad de su salud y construir el mito del pensador trágico (cf. Sánchez Pascual 2010). Lo que debemos investigar en nuestro contexto, y que se visualiza en la mayoría de sus aforismos, es el deseo de un aire nuevo para la filosofía, abarcando dimensiones insospechadas como la amistad y lo femenino. Nietzsche siempre manifestó la necesidad de nuevos lectores y nuevos oídos para su lenguaje de montañas; uno en que, "el camino más corto es el que va de cumbre a cumbre: más para ello debes tener piernas largas. Cumbres deben ser las sentencias: y aquellos a quienes se habla, hombres altos y robustos" (Nietzsche 2002b 73)

¿Podríamos entonces confirmar su sospecha de que entre sus contemporáneos no había oyentes y lectoras preparadas para ese tipo de verdades? Antes del filósofo de la genealogía, ¿existió un contrapunto femenino y filosófico capaz de interpretar moralmente la realidad, de la forma como él lo hizo? ¿En qué contexto y con cuáles pensadoras podríamos situar la conciencia de lo disímil en las interpretaciones valóricas de la realidad? ¿La perspectiva no complementaria de lo real conducen a la irremediable enemistad entre los sexos? Nos inclinamos a pensar que la tarea de la deconstrucción comienza en los textos y no en los cuerpos. Que eso de los cuerpos pasa por la percepción del otro, la construcción de una imagen: de la ficción y la recreación, del silencio impuesto, de la complicidad que poseen los discursos con el poder, además de nuestra majadera auto referencia cuando opinamos de objetividad.

Frente a esto no vale ser empático; acá existió un secuestro intelectual, un genocidio narrativo (no sé si existe una palabra o concepto adecuado para explicar eso de borrar de la historia humana la versión del otro sexo) Pero, ¿con cuantas más, con quiénes debemos retroceder para encontrar la voz del otro? Parece que transitamos una avenida de cruces invertidas, de seres amordazados, de mujeres aplacadas por el destierro de dios y por el peso de una imagen que asumieron como tal ¿Qué tan poderoso puede ser la construcción de un discurso sobre el otro?

Con el fin de esclarecer aún más este punto, a costo de desviarnos sobre el análisis de los textos nietzscheanos, expondremos sucintamente el pensamiento de 
algunas autoras que versan sobre la imagen femenina.

Existe un texto de Virginia Wolf redactado para una conferencia sobre novelas y autoras coloca en evidencia la falta de conciencia de género en la trama de la creación literaria femenina ( $c f$. Wolf 6 ). No obstante, esta escritora no fue la única ni la primera. En el contexto chileno Lucila Godoy Alcayaga, más conocida por Gabriela Mistral, comulgó con la marca de Caín haciendo de su desprecio generalizado la marca de su autoexilio. Polémica que subsiste aún hoy, generando controversias incluso entre sus congéneres.

Pero, ¿por qué no la queremos como deberíamos hacerlo? Quizás porque nunca quiso ser la madre de ninguna patria. El elemento biográfico de la primera novel latinoamericana generó aún más impacto al redescubrirse en ella una sexualidad refractaria, esa que dio pie a la rebosante pasión, critica y análisis que se desprenden de sus escritos, pero que también hubo de ser sometida a una manipulación ideológica que la redefinió más allá de su legado ${ }^{7}$.

El famoso verso de que "todas íbamos a ser reinas" edulcoró sus pasiones, sumiéndola en una docilidad que contaminó su imagen, de la misma manera que el enunciado del Zaratustra "no te olvides del látigo" creó al Nietzsche misógino.

"Todos le dijeron que no", dijo Gonzalo Rojas, declarándose mistraliano hasta la médula; su panegírico nos da una vaga idea de lo que debió experimentar la poetisa: "Le dijeron de todo: mediocre, impostora, retardataria, decimonónica. Desde las infancias debió soportar la suficiencia y la mala fe" (cf. Rojas XIII). Ella, sobre todo ella, experimentó el rechazo por poseer una sexualidad sin feminidad, por el vientre seco y su cama vacía, por esa sensibilidad de piedras, cerros y ventoleras y por esa espiritualidad profana (como si las Titánides le susurraran al oído); esa que escandalizó a la hipocresía devota de su época. Su reflexión sobre la mujer debería darnos algo de claridad:

A veces, yendo por las mismas entrañas de la cordillera, se descubre una casa perdida y como

7 Desde su muerte, la imagen de Mistral ha sido reinventada y manipulada, particularmente durante la dictadura militar del general Augusto Pinochet. En la década de 1970 y en la de 1980, fue manipulada como el símbolo del orden social y de la sumisión a la autoridad. Pese a su estrecha identificación con la maternidad y los niños, particularmente con los que eran indígenas o pobres, Mistral nunca contrajo matrimonio o tuvo hijos. A lo largo de su vida se vio acosada por rumores de que era lesbiana, y un pasaje de sus diarios revela su resentimiento ante eso. "Acerca de Chile, mientras menos se diga, mejor", escribió. "Incluso me han colgado este tonto lesbianismo, lo cual me hiere en una forma que no puedo siquiera poner en palabras. ¿Es posible ver una falsedad mayor?". Pero, en A Queer Mother for the Nation: The State and Gabriela Mistral (Editorial de la Universidad de Minnesota), Licia Fiol-Matta, catedrática asistenta de español y Culturas Latinoamericanas en el Barnard College, argumenta que "Mistral era una lesbiana de armario" y que su consagración póstuma como un ícono nacional célibe, santo, sufriente y heterosexual" contrasta con la realidad de su vida y obra ( $c f$. Rohter). 
"dejada de dios y de los hombres" (...) A poco mirar y oír se sabe que ese refugio metido en las alturas de los buitres es la industria de una sola mujer. Porque el hombre cordillerano no hace otra cosa que bajar a la mina, jadear persiguiendo las betas y dinamitar penas. El no cuida de sí, él no acierta a ablandarse un nido al igual que un buitre. Sino tiene a su costado a esta mujer, el resbala, día a día hacia la barbarie de los primeros indios. Y la índole de acción pura, de acción a todo trance que es la del varón chileno, desde Lautaro hasta Portales, parece arrebatar a su propia compañera a los quicios del sedentarismo y volviéndola su semejante. La mujer que vive junto a su ave de presa sobre la acidez de esas cumbres, resulta ser, conjuntamente un fenómeno y (...) una chilena que se halla en cualquier parte sea en las islas extremosas del sur, sea en Nueva York o en Paris (Mistral 246-247).

Pareciera que el texto hablara de una mujer que ve en el hombre a su igual, una mujer cómplice, mujer amiga. Ella es la que domestica a la naturaleza y rescata a su contrario; acá es el hombre el ser incompleto, viviendo en el peligro del abandono, más cerca del animal errante y del ave de rapiña si no logra retornar al nido que protege la mujer con el fuego. Pero la Mistral no calculó ni midió el peso del silencio y de la injusticia que experimentaron las mujeres de su época por la falta de retribución social o por la inexistente reciprocidad política. Quizás la mujer que describe la poeta ya no existe y sucumbió frente al ninguneo que ella misma padeció.

Otra mujer, hace muchos años atrás, Hildegart Von Bingen, penetró el corazón de la teología a través de sus visiones. El impulso de escribir, enmascarado por el misticismo, la protegía del acoso. Su propio rescate del anonimato implicó una alianza en torno a esas frágiles apuestas que empujan a magnos eventos. Su genialidad superó a cualquier homólogo masculino de su tiempo. ¿Resultó esa temeridad una amenaza? Sin duda, pero corremos el riesgo de tomar el camino del anecdotario y no reconocer la cruel paradoja a la que se vio forzada a recurrir para disfrazar la voz de su pensamiento.

La cuestión es que, para el racionalismo occidental representado por la voz de filósofos, poetas y artistas, la mujer es máscara de múltiples miedos y deseos. Apreciarlas es signo de inspiración, formar alianzas es asegurar victoria, traicionarlas es pagar una horrible venganza, estar en su contra es granjearse un enemigo implacable, comprenderlas es una lucha contra lo irracional; sentir atracción o estar bajo su dominio es caer en las artimañas de su brujería, rendirse a su lujuria es signo de desdicha. El miedo del hombre a la enemistad de la mujer no es una fobia infundada que tenga una cronología reciente, posee un pasado remoto en la construcción de la oralidad mitológica. El mito que, a nuestro entender, resume la incomprensión y los miedos masculinos es de Jasón y Medea (Grimal 297 336-337).

En conclusión, el modelo mitológico que permanece en nuestra oralidad y en nuestra conciencia es lo que Nietzsche pretende recrear. Tarea que implica la 
deconstrucción de la genealogía, pero que se torna imposible para esta "filosofía" y para estos "filósofos" que no intuyen la verdad de la mujer.

Esta "filosofía y estos filósofos" optan por los ideales ascéticos a los que Nietzsche hace mención en los parágrafos de la Genealogía de la Moral. Esto se ve representado en la voz de la multitud que corrige al sabio cuando este pretende reeducar a un joven en el parágrafo 68 de La Ciencia Jovial, titulado "Voluntad y docilidad". Esta lectura se torna crucial para comprender el pasaje del Zaratustra, "De viejecillas y jovencillas", y la supuesta enemistad del filósofo con la mujer:

Alguien llevó un joven a un hombre sabio y le dijo: “iMira, éste es uno que fue corrompido por las mujeres!". El hombre sabio meneó la cabeza y sonrió. "los hombres son", dijo, "quienes corrompen a las mujeres, y todo lo que falta a las mujeres debe ser pagado por los hombres y mejorado en ellos - pues el hombre se crea una imagen de la mujer, y la mujer se forma de acuerdo a esta imagen". "Eres demasiado generoso frente a las mujeres", dijo uno de los que se encontraban allí, "¡No las conoces!". El hombre sabio respondió "La voluntad es la índole del hombre, la docilidad es la índole de la mujer - esa es la ley de los sexos, ¡Verdaderamente! ¡Es una dura ley para la mujer! Todos los hombres son inocentes por su existencia, para las mujeres son inocentes en segundo grado: quién podría tener suficiente óleo y dulzura para ellas". - “¿Qué óleo" "qué dulzura" !, exclamó desde la multitud: “¡Hay que educar mejor a las mujeres!” - “Hay que educar mejor a los hombres", dijo el sabio, e hizo una seña al joven para que lo siguiese. - pero el joven no lo siguió (Nietzsche 1999 72).

El látigo de Nietzsche es el signo de la incapacidad de amistad que emerge desde el hombre hacia la mujer; la advertencia de la anciana remata la "supuesta" docilidad de lo femenino. Definitivamente Nietzsche no está del lado de la masculinidad patriarcal, exponiéndolo permanentemente a través de sus múltiples parágrafos. Aun así, el filósofo no es "dócil" frente a lo supuestamente "femenino" que es una creación masculina, porque la mujer no es lo que aparenta ser; todo lo contrario: esta mujer que permanece "secuestrada", está presente en todos sus libros, tratando el filósofo de liberarla de esa falsa imagen que la mantiene "raptada", y esto es más de lo esperaríamos de toda la filosofía occidental que lo precedió.

\section{La cuestión (bio)gráfica}

Las dudas presentes en la autoría del texto Mi hermana y yo ${ }^{8}$, nos hacen descartar el

\footnotetext{
${ }^{8}$ La prueba de la pérdida de la edición alemana original resulta menos creíble que oportunista. La quema, intencionada o fortuita, del manuscrito perjudica mucho más a la propuesta favorable a la autoría que a la contraría. Aunque es plausible suponer que la destrucción de los documentos buscaba evitar su uso para demostrar la autoría, es bastante más razonable concluir que la eliminación de ese presunto original, podía llegarse a una decisión común entre los especialistas a favor, pero también en contra; sin él, la duda perdurará para siempre ( $c f$. García 90).
} 
sentido próximo y reivindicativo de algunos parágrafos en el contexto de esta investigación. En la reflexión sobre las mujeres, Nietzsche no oculta un odio solapado y resentido del cual intenta retractarse. El análisis literario superficial, y la crítica apresurada por la llamativa experiencia vital que entrega el filósofo, han creado el mito del misógino y del incestuoso. Esto ha dañado cualquier tipo de contribución de la filosofía nietzscheana a los nuevos pactos y alianzas entre sexos, en materia de afectos y política (Patton 10).

Sostenemos que lo que realizó Nietzsche, con su particular estilo dramático, fue recrear el mito de lo femenino. Pero fiel a su estilo gráfico, utilizó sus martillos en contra de las pretensiones ilustradas e igualitaristas posibles de reconocer en las disputas de los movimientos feministas actuales: el golpe certero contra las máscaras. No obstante, el filósofo se hace un flaco favor y pavimenta los caminos del infierno con sus violentos y mordaces parágrafos.

¿Será, tal vez, que el filósofo había percibido el olor de ese cuerpo penitente (Dios) acechando la fuente de inspiración que los artistas, como él, habían hecho propio? Resulta plausible afirmar que Nietzsche, como un verdadero cazador de quimeras, expuso los valores decadentes y trascendentes en todos los rincones donde posó la vista.

Volviendo sobre el contenido biográfico, parece adecuado exponer la oposición de intereses entre los hermanos, la pésima apreciación materna y la idealización del padre, tópicos presentes en el polémico parágrafo 3 de "Por qué soy tan sabio", en Ecce homo (cf. Sánchez Pascual 2010). Pero desmenuzar la vida del filósofo buscando su leiv motiv no aporta al intenso desmoronamiento conceptual que logra al analizar la filosofía occidental, incluyendo la patética y abusiva percepción de lo femenino por parte de la filosofía que el intenta superar.

Es probable que Derrida haya sido quien intentó más claramente despejar la interrogante sobre la intervención de las disciplinas en torno al aspecto biográfico y creativo del filósofo. Lo rescatable de su análisis es haber puesto en evidencia la constante inte(rve)nción de Nietzsche -autor que intenta por medio de su estilo desautorizarse, a la vez, Nietzsche - hombre busca desenmascararse de su subjetividad a través del juego aforístico que lo instala como el filósofo de los enigmas (cf. Derrida 2009 33-34).

Queramos o no, él es también hijo de su tiempo y es justo decir que su filosofía sufrió un proceso de "muda de piel": los pensamientos del sujeto-hombre "mudan y fluyen" como las serpientes, (recordemos los animales emblemáticos de Zaratustra), y en esta dinámica de transformaciones el sujeto-autor del Zaratustra nos ha legado conceptos y aforismos con los que hemos debido lidiar permanentemente: "la afirmación nietzscheana, la afirmación gozosa del juego del mundo y de la inocencia del devenir, la afirmación de signos sin falta, sin verdad, 
sin origen, que ofrece a una interpretación activa" (Derrida 1967 400).

No podemos dudar de su propia palabra y tomarnos todo como una perversa ironía, producto de una extrema apropiación de un personaje que el mismo disfrazó como poeta filósofo, puesto que en el juego de los aforismos la finalidad es lograr incertidumbre, habilidad patente y característica de la matriz nietzscheana ¿Logró este poeta filósofo preformar el mito de lo femenino? Parece ser que el profeta intempestivo del Zaratustra sobrepasó al poeta de La Ciencia Jovial, permaneciendo así con su cruel evaluación de la verdad.

\section{Conclusiones provisorias}

Para concluir, sostenemos que la recepción de la propuesta nietzscheana adoleció de los elementos deconstructivos esenciales para su interpretación; paradojalmente, el mismo filósofo dejó claves que fueron mucho más que simples insinuaciones en cada uno de los libros que antecedieron al Zaratustra, sobre todo en la II Intempestiva (cf. Nietzsche 2006 82). En ella podemos reconocer un abordaje más conceptual sobre el tema que investigamos: la mujer como un "eterno femenino" que los "eunucos" son incapaces de distinguir, como si no hubiésemos reconocido que Nietzsche en cuestión de estilos también sufrió transformaciones: de filólogo a filósofo, de filósofo a poeta, de poeta a esteta, y es con el esteta-autor con el que tenemos deudas interpretativas pendientes.

¿Por qué nosotros, los filósofos del futuro, no logramos dilucidar el potencial simbólico de su magna obra? ¿Acaso no fuimos capaces de escuchar las advertencias que el mismo tan majaderamente recalcó?: "No me entienden: no soy yo la boca para estos oídos" (Nietzsche 2002b 42). No es parte de esta indagación resolver la cuestión de si sus lecturas fueron manipuladas para el beneficio de terceros. En tal medida lo sensato sería preguntarnos:

¿Qué es lo que finalmente representa la mujer en los capítulos del libro primero del Zaratustra? Nietzsche en el capítulo completo "Del amigo", realizó un retrato, línea por línea, pensamiento por pensamiento, de lo que él estima y evalúa como la amistad femenina, pero permaneciendo fiel a su estilo dramático simula una conversación con una mujer (distinto caso cuando Zaratustra se encuentra con ambas mujeres). Es como si preguntara: ¿Soy yo tu amigo? ¿Me consideras como un amigo? Este diálogo no solo representa una conversación entre sexos opuestos sino también entre el filósofo y la sabiduría-mujer. Personifica también la amistad del verdadero filósofo-esteta (no la del eremita solitario que solo ve compañía en el diálogo con su conciencia, al que ya menosprecia desde la primera línea del capítulo).

Parece decirnos que debería ver en su compañero, en este caso, compañera, 
un amor a la sabiduría, amor a la verdad, verdad que es mujer (verdadero opuesto: ella, la señora del laberinto, la esposa de Dionisio, Ariadna).

El potente símbolo de desciframiento de la verdad en torno al enigma lo reconocemos en el dios Apolo y en su acción a distancia a través del oráculo, siendo la mujer el puente y el canal de su mensaje - la pitia, el arco y la lira armonía y fatalidad. Siguiendo la interpretación de Colli en el Nacimiento de la Filosofía (cf. Colli 2010), la mujer es quien descifra el laberinto y es por antonomasia dueña de los secretos velados; ella es Ariadna, amante de Teseo y esposa de Dionisio. Pero antes de esa relación de matrimonio divino, el mito presenta versiones opuestas: la figura de Ariadna es abusada sexualmente y abandonada a su suerte, como tantas otras mortales en manos de los dioses.

Ariadna es una mujer, pero también según el testimonio escrito, primordial sin duda alguna, una diosa, "la señora del Laberinto". Esa doble naturaleza, divina y humana, de Ariadna, esa ambigüedad suya radical, nos lleva a una interpretación simbólica, del que probablemente sea el mito griego más antiguo, el mito cretense de Minos, Pasifae, el Minotauro, Dédalo, Teseo y Dionisio. Ariadna es la única figura femenina que el mito griego en general presenta unida a Dionisio de modo explícito y directo, como esposa (Colli 25-26).

Al mismo tiempo, las líneas finales del capítulo "Del amigo" muestran la incapacidad de amistad fruto de la enmascarada masculina sobre lo femenino. Por eso el filósofo nos deja como consuelo algunas preguntas por responder: ¿Qué es lo prohibido de recrear a la mujer- verdad, de seducir a la mujer-enigma y dejarnos atrapar por la mujer-laberinto? ¿Qué signo de debilidad es la mujer-amigo? ¿Qué prueba de fortaleza es la mujer-enemigo? ¿No es acaso el filósofo amante, amigo y enemigo quien desea torpemente, pero que al mismo tiempo rechaza a esta mujersabiduría? ¿No es esa ambivalencia el signo de la misoginia que ostenta la filosofía moderna, platónica y kantiana? Como "gatas y pájaros", nadie tuvo el valor de descifrar este bestiario, ya que enfrentar la domesticación y la liberación en un mismo párrafo podría haber resultado arriesgado incluso para el más audaz de sus discípulos ¿Quién subyuga al vacuno servil y explotado?: "vacas siguen siendo en el mejor de los casos", nos dice.

Lo certero sería decir, en el peor de los casos, reservándonos la duda de la ironía y el sarcasmo nietzscheano. Pero la referencia bovina es una clara alusión al mito cretense: Ariadna y Dionisio, Zaratustra es Dionisio, la única pareja estéticamente adecuada para tal magno personaje. Nietzsche en ningún momento de su libro detiene el torrente simbólico, transformándose en la panacea de las (auto)referencias, de los libros anteriores y posteriores al Zaratustra. Sin decirlo, sin percatarse, solo advirtiéndolo, dejó trabajo e intrincados laberintos que no logro nunca imaginar. El gesto más per formativo de la obra de Nietzsche, quien solo nos 
legó signos: "Símbolos son todos los nombres del bien y del mal: no declaran, sólo hacen señas, “¡Tonto es quién de ellos quiere sacar saber!” (Nietzsche 2002b 124).

Siguiendo la lectura del Zaratustra, el filósofo arremete con la sentencia que presume el látigo al andar con mujeres ¿Cuál es la cruel paradoja de la anciana y su consejo? ¿A quién representa? ¿Al cuadro de las tres edades? ¿Al pesimismo de Schopenhauer? Pero, finalmente, debemos comprender que la viejecilla es la máscara que sostiene al género tras siglos de silencio y abuso que Zaratustra no logra descifrar, porque a los ojos de esta mujer es solo un niño que no entiende y no sabe sobre mujeres, al cargar con el peso de una racionalidad masculina que ninguno, ni el más astuto de todos los hombres, puede desatender. Ese parece ser el signo, la llave interpretativa. Esto nos conduce a releer el polémico párrafo que hace la distinción entre "tener razón sobre algo" versus el "conocer algo". Precisamente, eso que creemos entender es lo que no conocemos de la mujer: “¡Es extraño, Zaratustra conoce poco a las mujeres, y, sin embargo, tiene razón sobre ellas!" (Nietzsche 2002b 111)

Finalmente, planteamos que los polémicos capítulos del Zaratustra se deben leer a luz de parágrafos dispersos en los libros anteriores, sobre todo los de $\mathrm{La}$ Ciencia Jovial y Humano demasiado humano. Eso permitiría visualizar, provisionalmente, la punta del iceberg. Desde este prisma el legado nietzscheano corresponde a la función de una genealogía pendiente sobre el mito de lo femenino.

\section{Bibliografía}

Aristóteles. Ética Nicomáquea. Madrid: Gredos, 1993.

Castrillo, Dolores. "La filosofía de Nietzsche como filosofía de máscaras". Nietzsche, F. Así hablo Zaratustra. Madrid: Edaf, 2012. 40-41.

Cirlot, Victoria. Hildegard Von Bingen y la tradición visionaria de occidente. Barcelona: Herder, 2012.

Colli, Giorgio. Introducción a Nietzsche. México: Folios, 1983.

-. El nacimiento de la filosofía. Buenos Aires: Tusques, 2010.

De Beauvoir, Simone. El segundo Sexo. Santiago de Chile: Penguin Randon House S.A., 2018.

Deleuze, Gilles. Nietzsche. Madrid: Arena Libros, 2000.

Derrida, Jacques. La escritura y la diferencia. Barcelona: Anthropos, 1967.

-. Espolones, los estilos de Nietzsche. Valencia: Pre-textos, 1981.

—. Políticas de la amistad seguido de El oído de Heidegger. Madrid: Trotta, 1998.

-. Otobiografias, la enseñanza de Nietzsche y la política del nombre propio. Madrid: 
Amorrortu, 2009.

Foucault, Michel. La arqueología del saber. México: Siglo Veinte uno, 1970.

—. Nietzsche, la genealogía, la historia. Madrid: PRE-TEXTOS, 1997.

—. La Hermenéutica del sujeto. México, D.F.: Fondo Cultura Económica, 2002.

Frei, Raimundo. Retratos de la amistad. Santiago de Chile: LOM, 2012.

Freud, Sigmund. «Obras Completas, vol. XIII, Tótem y tabú y otras obras.» Freud, Sigmud. IV. El retorno del totemismo en la infancia. Buenos Aires: Amorrortu editores, 1991a.

-. «Obras Completas, vol. XXI, El porvenir de una ilusión, El malestar en la cultura y otras obras.» Freud, Sigmud. El malestar en la cultura. Buenos Aires: Amorrortu, 1991b.

García, Miguel Ángel. “'Mi hermana y yo', ¿obra de Nietzsche?”. Metafísica y persona. Filosofía conocimiento y vida (2009): 85-104.

Grimal, Pierre. Diccionario de mitología griega y romana. Buenos Aires: Paidós, 2008.

Han, Byung-Chul. La expulsión de lo distinto. Barcelona: Herder, 2014.

Jara, José. Nietzsche; Un pensador póstumo, Anthropos Editorial, Barcelona, 1998

Lussich, Dolores. "La mujer y lo femenino en el pensamiento de Friedrich Nietzsche". Actas del XV Congreso Nacional de Filosofía AFRA. Buenos Aires: EDUNTREF, 2012. 235 - 300.

Mistral, Gabriela. Vivir y escribir, prosas autobiográficas. Santiago de Chile: Ediciones Diego Portales, 2015.

Münnich, Susana. Nietzsche: la verdad es mujer. Santiago de Chile: LOM, 2011.

Nietzsche, Friedrich. La ciencia jovial. Caracas: Monte Ávila Eds., C.A., 1999.

-. El anticristo, maldición sobre el cristianismo. Madrid: Alianza Editorial, 2002a.

-. Así habló Zaratustra. Madrid: Alianza Editorial, 2002b.

- Ecce Homo, cómo se llega a ser lo que se es. Madrid: Alianza, 2005.

- Sobre la utilidad y el perjuicio de la historia para la vida (II intempestiva). Buenos Aires: Libros del zorzal, 2006.

- Más allá del bien y del mal, preludio de una filosofía del futuro. Madrid: Alianza, 2007.

Patton, Paul. Nietzsche, Feminism and political theory. London-New York: Routledge, 1993.

Rohter, Larry. 7 de julio de 2003. “Gabriela Mistral: Poeta y Lesbiana”. Los Tiempos. The New York Times News Service. [visitado 8 de marzo de 2019]. www.eltiempo.com/archivo/documento/MAN-995948

Rojas, Gonzalo. Gabriela Mistral en verso y prosa, Antología. Lima: Alfaguara, 2010.

Schopenhauer, Arthur. El mundo como voluntad y representación. Madrid: Alianza Editorial, 2015. 